\title{
Assessment on Ecological Distribution of 'Crematogaster chiarinii' ant in South-western Ethiopia
}

\author{
Tesfu Shegaw \\ Bonga Agricultural Research Center, South Agricultural Research Institute (SARI), Bonga, Ethiopia
}

\section{Email address:}

tesfushegaw68@gmail.com

\section{To cite this article:}

Tesfu Shegaw. Assessment on Ecological Distribution of 'Crematogaster chiarinii' ant in South-western Ethiopia. Science Research. Vol. 8, No. 3, 2020, pp. 84-89. doi: 10.11648/j.sr.20200803.13

Received: December 20, 2019; Accepted: April 21, 2020; Published: June 23, 2020

\begin{abstract}
The study was conducted in selected districts of kafa, sheka and Benchi maji zones of Southern Nations Nationalities and Peoples Region of Ethiopia with an intention to identify the agroecological distribution level of cr. chiarinii ant. The study was under taken through collection of survey data from respondent beekeepers and conducting transect views. According to the survey result, of the total transect views covering $167 \mathrm{kms}$ distances with 50 meters horizontal width and observation covered altitudes ranging from 800 to 2400 m.as.l. Nearly equivalent transect distances were considered for each agro ecologies (High land, mid land and low lands containing 60, 50 and 57 kilometers respectively). A total of 497 nests were counted during the transect. Of which 387 (77\%) were counted in mid lands (1500-1900 m.a.s.1.); 60 (12\%) of the nests counted in low lands (<1500 m.a.s.1.) and 50 (10\%) of them were counted in high lands (>1900 to 2400 m.a.s.1.). The Proportions of respondents using Cr. chiarinii as biological protection means against D. quadratus varied from $19.17 \%$ in Benchi Maji zone to $43.33 \%$ in Sheka zone whith an overall mean of $27.78 \%$. There is no significant varriation between male and females (at $\mathrm{p}<0.05)$ in using Cr. chiarinii as a potential biological pest prevention mechanism $(28.4 \%$ versus $20.69 \%)$. In the curent study, the distribution of the ant was higher in mid lands (1500-1900m.a.s.l) and declining as we go up over 1900 m.a.s.l and lower than 1500 m.a.s.l. Particularly, in areas of extreme low altitudes the ant was noted to be very selective to areas with better moisture contents and is highly selective to areas with old trees and better vegetation cover is found. However, it is not selective to plant types and its distribution gets declining in areas with less forest coverage and intenssive cultivation is under taken.
\end{abstract}

Keywords: Crematogaster Chiarinii, Distribution, Agroecologies

\section{Introduction}

Ethiopia is one of the countires enriched with diverse agroclimatic features favoring for the existence of diverse florals and founas [1, 12, 13, 18, 19] and [22] which supports an estimate of 12 Million honeybee colonies grouped into five distictive races being $A$. m. scutellata, A. m. monticola, A. m. bandansi, A. m. woyi gambella and A. m. jementica [3, $10]$. However, the diverse agro climatic features are not only favorable for honeybees but also favors the existence of various pests and predators which will directly or indirectly affecting honeybees and their products [9]. This includes ants $(50.1 \%)$, wax moth $(15.6 \%)$, spider $(9.5 \%)$, lizard $(8.9 \%)$, birds (11.7\%) and honey badger (4.2\%) [5]. Of the listed pests and predators, ants particularly the black ant (Dorylusspecies.) shares the greatest grievances in causing serious devastation of honeybees in most areas of the country; especially, the incidence is very intense in moist and humid areas of the country by consuming all the bees' resources including honey, pollen, brood and even adult bees $[8,9,14]$. According to study conducted in west and southwest Shoa zones, the economic losses of beekeeping due to ant attacks is estimated to reach $3,839,810$ Ethiopian Birr annually [8]. This revealed the economic losses due to this pest are incredibly high country wise which is estimated to be about $29 \%$ of the total produce [10].

The South and South western parts of Ethiopia, due to its huge vegetation cover emaneting from it highly moist and humid climatic features is very ideal for the existence of varrious ant species. Particularly, the black ant (Dorilus Quadratus) is highly abundant in the areas and shares the greatest griviences on honeybees resulting for huge 
economic losses from beekeeping subsector [7, 17] and [21] So far, varrious mechanical protection mechanisms; such as inner tube, smooth iron sheet and tin filled with used engine oil, commonly practiced by most beekeepers of the country [10]. The communities in Kafa, Shaka and Benchimaji zones are also using varrious local mechanisms to protect the attacks of ants such as tying "teff" straw on the hive stands, putting ashes around the hive stands, distructing the queen of ants, spryaying insecticides after digging its nest and then covering, adding hot water in its nest, tying peace of hungover on the stem of trees where hive hunged, etc. However, due to varrious attacking mechanisms of the ant mostly these protection mechanisms are not fully successful [4]. Hence, development of efffective and applicable pest protection mechanisms are highly warranted. Application of biological agents for preventing or controlling honeybee pests through acting as predators, parasitoids or pathogens is essential in ensuring effective integrated pest management schemes [15].

According to recent studies, using 'crematogaster chiarinii' ant was found to be one of the best pest protection mechanisms biologically against the notourious ant species [17]. So far, despite the study under taken to identify this ant as one of the best options in protecting the pest, there is no detailed information on its biological distribution level and the community status in using the ant as apotential biological pest protection measures. Assessing and appreciating the roles and relevance of the novel local practices in beekeeping and other agricultural activities can help in attaining an attempt to bridge the gap with scientific Knowledge, improving ecological development and achieving sustainable development [2] and [23]. Hence, the current study was principally entended with identifying the ecological distribution of this ant and determinant factors for its survival so as to utilize the ant in protecting the notorious pest in order to increase the backyard beekeeping practices and identifying the practical aspects of communities in using the ant for economical purposes.

\section{Materials and Methods}

The study was conducted in Kafa, Sheka Bench Maji zones of Southern Nations Nationalities and Peopels region. The area has a total of 20 districts (i.e. 10- in Kafa Zone; 7in Benchi Maji zone and 3- in Sheka Zone). Out of which 6districts were purpossively selected from three zones (i.e. Chena, Gimbo and Gewata from Kafa zone; Guraferda and Debub Benchi districts from Benchi maji zone and Anderach district from Sheka zone) and three PAs were selected from each district representing High land, Mid land and Low land agro ecologicies to collect the relevant information.

\subsection{Collection of Questionnaire Survey Data}

The questionniare survey data was collected from purpossively selected beekeepers based on their beekeeping experiences. Accordingly, twenty beekeepers were involved in the interview from each PA adding to total of 360 individuals from three study zones.

\subsection{Collection of Transect View Data}

The transect view data were collected from each three PAs of selected districts representing High land, Mid land and Low land agro ecologies. After selecting the PAs, a reconnausence survey was conducted at each PA before the commencemnet of actual transect views to determine the transect directions and distance based the varriations existing in land use patterns as intact forests, Partially disturbed forests, cultivated lands with populated trees, intensively cultivated areas with dispersed trees, riverines/swampy areas and agroforestries. Nearly equivalent distances of transects were under taken per each land use patterns in each agroecologies. A total of eighteen PAs were used to collect the transect data. The lowest and highest altitudinal gradients were considered while selecting the PAs and nearly equivalent transects were considered. The total areas of land covered during the transect route of each land use pattern, altitudes, vegetational covers, distance among each consequitive nests were determined using GPS. The land use patterns were classified as natural forests, cultivated areas, agro forestries and riverines. Based on the land use patterns and vegetational covers, the ant nest distribution was compared among ecosystems of Intact forests, partially disturbed forests, cultivated areas with populated trees, cultivated areas with sparsely populated trees, riverines and Agro forestries. The selectivity of the ant to plant types was determined by comparing the number of nest and relative abundance of the plant in an area with an assumption that if the ant is selective to a particular plant it has no correlation with its relative abundance and the reverse is true.

The transect obseravion was undertaken within 25 meter radius to both sides of transect routes.

The relative abundance of each plant type was determined using Shannon-Wiener Index (H') calculations.

$$
\text { Rel. density }(\mathrm{RD})=\frac{\text { Density of a species in a plot }}{\text { Total frequency of plants in a plot }} \times 100
$$

The relative density (RD) of each nesting plant was estimated by counting plants within an area of one hectar land considering 50 meter radius distance from each nest. The altitudinal varriations were classified as three major agro ecological categories as Low lands which is $<1500$ m.a.s.; Mid lands from 1500 to 1900 m.a.s. and High lands $>1900$ meters above sea level (m.a.s).

\section{Methods of Data Analysis}

The distribution level of "Crimatogaster chiarinii" with regard to Agro ecologies, land use patterns, plant and soil types were analyzed using SPSS-20 statistical soft wares. The correlation between abundance of nest with relative abundance of plant types, land use patterns, vegetation coevers were analyzed using Chi-square test. 


\section{Result and Discussion}

\subsection{Age Distribution and Beekeeping Experience of Respondents}

According to the result in Table 1, the respective average age of beekeepers was found to be $37.15 \pm 8.3 ; 40.04 \pm 8$ and $40.19 \pm 9.08$ for kafa, Sheka and Benchi Maji zones suggesting that beekeeping is mostly practiced by younger age groups of the community. Interms of gender, female farmers engaged in beekeeping are relatively younger than male (35.75 vs 39.79 ). The proportion of beekeepers using Cr. Chiarinii as biological control against D. quadratus varried from $19.17 \%$ in Benchi Maji zone to $43.33 \%$ in Sheka zone with an over all mean of $27.28 \%$. There was no significant gender effect (28.4\% male and $20.69 \%$ females) in using the ant as pest prevention mechanisms at the sites included in the study areas at $\mathrm{p}<0.05$.

Table 1. Background of the beekeepers in using cr. Chiarinii as apotential biological pestprevention mechanism.

\begin{tabular}{|c|c|c|c|c|c|}
\hline Zones & Sex & $\mathbf{N}(\%)$ & $\begin{array}{l}\text { Age of beekeepers } \\
(\text { Mean+SD) }\end{array}$ & $\begin{array}{l}\text { Beekeeping expriences (Mean+SD) } \\
\text { of respondents }\end{array}$ & $\begin{array}{l}\text { Number of beekeepers using } \mathrm{Cr} \text {. } \\
\text { chiarinii as pest prevention }\end{array}$ \\
\hline \multirow{3}{*}{ Kafa } & Male & $165(91.7 \%)$ & $38.65+7.83$ & $10.68+7.43$ & $47(28.48 \%)$ \\
\hline & Female & $15(8.3 \%)$ & $35.29+6.28$ & $5.7+3.4$ & $4(26.67 \%)$ \\
\hline & Total & $180(100 \%)$ & $37.15+8.3$ & $9.84+7.2$ & $51(28.33 \%)$ \\
\hline \multirow{3}{*}{ Sheka } & Male & $55(92 \%)$ & $40+8.5$ & $13+7.49$ & $24(43.64 \%)$ \\
\hline & Female & $5(8 \%)$ & $38.29+9.28$ & $11.8+6.34$ & $2(40 \%)$ \\
\hline & Total & 60 & $40.04+8.54$ & $13.05+7.49$ & $26(43.33 \%)$ \\
\hline \multirow{3}{*}{ BenchiMaji } & Male & $111(93 \%)$ & $40.72+9.03$ & $12.27+6.7$ & $23(20.73 \%)$ \\
\hline & Female & $9(7 \%)$ & $33.67+7.42$ & $6.44+5.39$ & - \\
\hline & Total & 120 & $40.19+9.08$ & $11.83+6.76$ & $23(19.17 \%)$ \\
\hline \multirow{3}{*}{ Overall } & Male & 331 & $39.79+8.13$ & $11.98+7.23$ & $94(28.4 \%)$ \\
\hline & Female & 29 & $35.75+8.02$ & $7.98+5.33$ & $6(20.69 \%)$ \\
\hline & Total & 360 & $37.77+8.09$ & $9.96+6.05$ & $100(27.78 \%)$ \\
\hline
\end{tabular}

\subsection{Beekeepers Experience in Identifying and Using Cr. Chiarinii}

According to the survey findings, there are about three other species found in the area which are closely related to $c r$. chiarinii. However, locally $c r$. chiarinii ants can be differenciated from other related species based on morphological features of the ant body and their nests such as size and color of the nest, colour of the ant body, size and shape of their abdomen and their biting intensity. This agrees with previous findings that this ant is very diverse in its nature reaching over 460 species world wide [6].

Accordingly, $c r$. chiarinii has bigger nest sizes than relative other species; its nest is apparently black in colour and the ant has prominent body sizes and black in colour. It has bigger and close to oval shape abdomen than related species which have thinner and small abdomen and redish in colour. Some of the ants are more iritating when biting and some are not biting at all. However, crimatogaster chiarini are midium in its biting intensities and has distictive odour. More than $80 \%$ of the respondents replied that the nest and its colony may stay for longer even more than ten years and intense multiplication will takes place during wet seasons (through May to October).

The multiplication will take place by forming individual colony surrogated from its mother and forming independent colony near to the mother nest. It may construct its nest at a shortest hight even upto 1 meter from the ground and as high as 20 meters and more from the ground. Mostly, the nest is situated beneath the branches/stems/in a position not exposed to rain falls. In this regard, some farmers also practice piersing its nest and exposing for rainfall when they need to distroy the ant.

Of the total 360 interviewed beekeepers 100 (27.78\%) are using $C r$. Chiarinii as a potential biological pest protection mechanisms. Of whom about $90 \%$ are using through hanging the hives on trees containing the nest; by doing so, the Dorylus ant can't climb on trees containing the crimatogaster chiarinii nest as it can spread over the whole stem while foraging. However, $10 \%$ of beekeepers are practicing adapting the ant by transporting the colony with its nest to their backyards/apiaries by hanging on nearby trees.

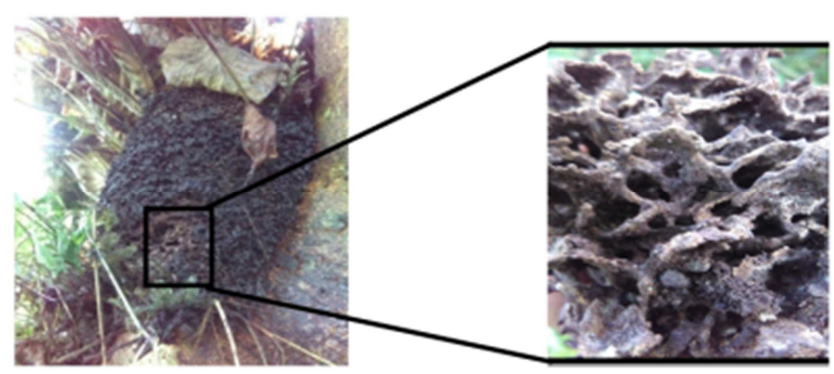

Figure 1. Nest of Cr. Chiarinii.

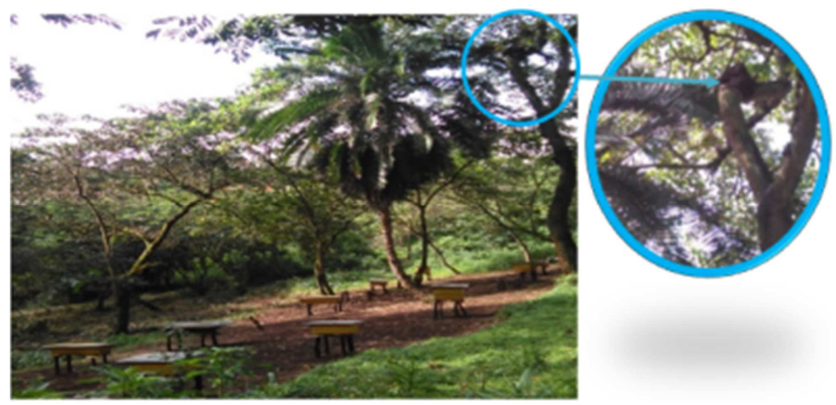

Figure 2. Cr. Chiariniiaddaptedatapiaries. 


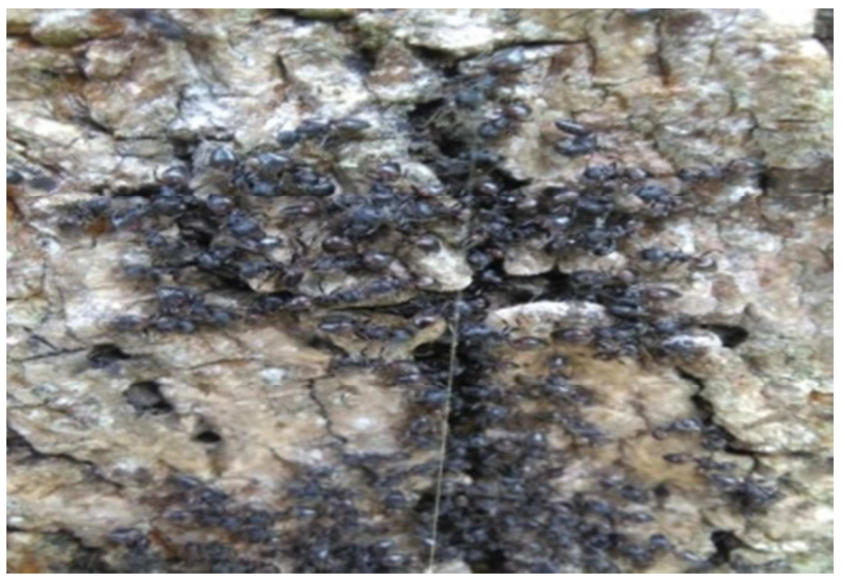

Figure 3. Cr. Chiarinii accumulated on bark of tree.

\subsection{Distribution Rates of Cr. Chiarinii}

The transect covers a total distance of $167 \mathrm{~km}$ (i.e. 60,50 and $57 \mathrm{kms}$ in high land, mid land and Low land agroecological zones respectively. According to the result of transect views, there were a total of $497 \mathrm{Cr}$. chiarini nests were counted through the transect; Of which 387 (78\%) were counted in mid lands (1500-1900 m.s.l); 60 (12\%) of them were counted in low altitudes below 1500 m.a.s.l. and 50 $(10 \%)$ of them were counted in high lands (>1900m.a.s.1) (Table 2). The respective distances (Mean $\pm \mathrm{SD}$ ) among nests was computed as $2.92 \pm 2.47 \mathrm{~km}, \quad 0.402 \pm 0.74 \mathrm{~km}$ and $2.18 \pm 2.16 \mathrm{~km}$ for high lands, Mid lands and low lands.

According to the result on comparison of the mean distances among nests along the altitudinal gradients showed that it is getting more sparse as we go to areas below $1500 \mathrm{~m}$ a.s.l. and highly sparse $(5.45 \pm 4.03 \mathrm{~km})$ at extremly low altitudes (<900 m.a.s.l) (Table 2).

Similarly, it was found to be $1.22 \pm 1.44 \mathrm{~km}$ at altitudes 1900 to 2000 m.a.s.l. and has got maximum distances $(4.41 \pm 3.27 \mathrm{~km})$ at altitudes 2000 to 2400 m.a.s.l. The mean distances between nests in the studied areas was found to be $0.8 \mathrm{~km}$ (Table 2). This shows the ant is naturally more selective to Mid altitudes (1500-1900m a.s.1). Out of the total nests in low lands, about $80 \%$ of them were counted in riverine/water logging areas. This might be due to the reason that the ant is more selective to wet areas to survive and effective multiplication. The current finding agrees with previous study reports that the ant is more preferable to areas with higher pricipitation over $1000 \mathrm{~mm}$ per annum. Whith regard to vegetation covers, $C r$. chiarinii is widely distributed in areas with higher forest covers than fragemented forest areas. This should be related with the ants behaivor as it needs plant ruins for constracting their nests as well as extracting their feed sources from the plants and insect excretions in it [17] With regard to plant coverages, the distribution level is significantly higher in intact and partially disturbed forests than spersely populated forests and cultivated lands. But, the distribution is insignificant between intact forests and partially disturbed forests. This is in agreement with the previous studies that the existence of the ant could be affected by the availability of food and nesting resources which relied on the vegetation diversity and structural complexity which could determine the abundance of diverse animals, fungi and microorganisms inter dependent on each other [16] and [20]. Of the total nest, more than $90 \%$ of them were counted on larger trees. This is maily related with the habit of the ant that it can obtain its feed and nesting renminants from barks and crevices of larger/old trees.

Table 2. Nest densities based on Agro ecologies.

\begin{tabular}{llllll}
\hline Altitude (m.a.s.l.) & N $(\%)$ & AEZ & Mean \pm SD $(\mathbf{k m})$ & Range $(\mathbf{K m})$ & Nest densities by AEZ $($ Mean \pm SD) $(\mathbf{k m})$ \\
\hline$>2000-2400$ & $16(3 \%)$ & HL & $4.41 \pm 3.27$ & $1.24-11.19$ & $2.92 \pm 2.47$ \\
$>1900-2000$ & $34(7 \%)$ & HL & $1.22 \pm 1.44$ & $0.010-13.42$ & $0.003-6.77$ \\
$>1500-1900$ & $387(77 \%)$ & ML & $0.402 \pm 0.74$ & $0.402 \pm 0.74$ \\
$900-1500$ & $51(10 \%)$ & LL & $1.28 \pm 1.53$ & $0.021-12.23$ & $2.18 \pm 2.16$ \\
$<900$ & $9(2 \%)$ & LL & $5.45 \pm 4.03$ & $0.038-21.43$ & $0.80 \pm 1.45$ \\
Total & $497(100 \%)$ & & $0.80 \pm 1.45$ & $0.003-21.43$ & 0.45 \\
\hline
\end{tabular}

$\mathrm{N}$ - Number of nests counted; AEZ-Agro ecological zones; SD-Standard Deviation; km- kilometers

The selectivity of the ant to plant types was identified by comparing the number of nests found on a aparticular plant with the relative density of the plant. The relation of nest distribution with plant type was investigated using 'Pearson correlation' methods. With an assumption that if the ant is selective to a particular plant species, the number of nests counted on that particular plant will not be corelated with the relative abundance of the plant and viceversa. According to the survey results, the ant will exist on any plant types and has no significant correlation on selectivity $(\mathrm{P}<0.05)$ (Table 3 ). With regard to land use patterns, the ant is very sparsely found in agroforestries/plantation areas. Whereas, it is highly distributed in areas with natural forests. This might be related with the less amount of folliages found in agroforestries compared to natural forests.

Table 3. The correlation of plant density and number of nests.

\begin{tabular}{lll}
\hline Agroecologies & Correlationofnestswithplantabundance & P-value \\
\hline Lowlands & 0.444 & 0.033 \\
Midlands & 0.542 & 0.020 \\
Highlands & 0.30 & 0.041 \\
\hline
\end{tabular}

\section{Conclusion and Recommendation}

In the current study it was noted that the beekeepers' awareness and the practices of using Cr. chiarinii as a potential biological pest prevention mechanisms is very low. On the other hand, existance of other closely related species remained one of the main challenges in identifying the 
species by some beekeepers. Hence, training and experience sharing with more advanced beekeepers in using the ant is imperative. According to the survey result on its distribution the ant was highly abundant in midlands (1500-1900 m. a.s.1.) and less abundant at extreemely high and low altitudes over 1900 and below 1500 m.a.s.l. This shows the ant is more sensitive for rain fall amount and temperatures. It was found to be selective to areas where better moisture contents of the soil is found in low altitudes less than 1500 m.a.s.l. The ant was not selective to plant types. However, it is more selective to areas where old trees and higher vegetation cover is found. This revealed measures taken to maintain forest ecosystem has a direct implication to keep the composition of biodiversities in general and halting extinction of economically important species in particular. In this regard persuing intergrated agricultural practices in focus of non timber forest products including forest beekeeping can hasten forest conservation which intern favors attaining conserving biodiversities. The soil texture of the study areas are predominantly tending to loamy types and more of acidic in nature. Hence, evaluating adaptability of the ant other than its natural habitat considering different soil types should be undertaken in order to exploit the ant as a potential biological pest prevention mechanisms at large. More over, detailed biological identification of the ant including its food chain, ways of perpetuation, chemical composition of its pheromones and other economic benefits require follow up studies.

\section{References}

[1] Abadi, B., Abebe, A., Delenasaw, Y. 2016. Community Perception on Beekeeping Practices, Management, and Constraints in Termaber and Basona Werena Districts, Central Ethiopia. Advances in Agriculture, Volume, 2016. http://dx.doi.org/10.1155/2016/410643

[2] Abebe, S., Bereket, D., Kahsay, B., Azage, T., Dirk, H. 2009 Recognizing Farmers' Knowledge in Development Initiatives: Indigenous Beekeeping in Alaba Special Woreda, Southern Ethiopia. Paper presented at $16^{\text {th }}$ International Union of Anthropological and Ethnological Sciences (IUAES) World Congress from July 27-31/2009 in China, Yunnan (Kunming).

[3] Amssalu, B., Nuru, A., Radloff, S. E. and Hepburn, H. R. 2004. Multivariate morphometric analysis of honey bees (Apis mellifera) in the Ethiopian region. Apidologie, 35 (1): 71-81.

[4] Awraris, G., Yemisrach, G., Dejen, A., Nuru, A., Gebeyehu, G. and Workineh, A. 2012. Honey production systems (Apis mellifera L.) in Kafa, Sheka and Bench-Maji zones of Ethiopia. Journal of Agricultural Extension and Rural Development Vol. 4 (19), pp 528-541. Available online at http://academicjournals. org/JAERD

[5] Birhanu, T. 2016. Constraints of Opportunities of Honeybee production and honey marketing system: A case of Guji and Borena of Oromia state. Department of Animal and Range Science. Bule hora University, Ethiopia.
[6] Bonnie, B. 2012. A subgeneric revision of Crematogaster snd discussion of Regional species groups (Hymenoptera: Formicidae). Zootaxa $\quad 34-67 \quad$ (2012). http://www.mapress.com/zootaxa/.

[7] Chala, K., Taye, T., Kebede, D., Tadele, T. 2012. Opportunities and challenges of honey production in Gomma district of Jimma zone, South-west Ethiopia. Journal of Agricultural Extension and Rural Development Vol. 4 (4), pp. 85-91.

[8] Desalegne, B. 2015. A review on Honeybee diseases and Pests research progress in Ethiopia. African Journal Of insect, Vol. 3 (1): pp 093-096.

[9] Desalegne, B. 2016. Some Major pests and Predators of honeybees in Ethiopia. The $8^{\text {th }}$ Ethiopian Beekeepers Association Proceeding, August 2016. addis Ababa, Ethiopia.

[10] Desalegne, B., Gemechis, L., Kibebew, W., Zewdu, A., Alemayehu, G., Dereje, W. 2015. Apiculture Research Status and Achievements in Ethiopia. Collection of Abstracts. Oromia Agricultural Research Institute (OARI), Holeta Bee Research Center, Holeta Ethiopia

[11] Desalegne, B., Gemechis, L., Melaku, G. 2016. Promotion of Beekeeping in the rural sector of Ethiopia. The $8^{\text {th }}$ Ethiopian Beekeepers Association Proceeding, August 2016, SAMKET printing, Addis Ababa, Ethiopia.

[12] Haftey, S., Gashaw, E., Ayalew, N., Tsehaye, N. 2018. Assessment of honey production system, constraints and opportunities in Ethiopia (Review). Pharmacy \& Pharmacology International Journal, Volume 6, Issue 1.

[13] Hailemikael, T. 2018. A review on: The status of beekeeping practices and honey production system in Ethiopia. International Journal of Engineering Development and Research. Vol. 6, Issue 2. http://www.ijedr.org

[14] Hayilegebriel, T. 2014. Honey Bee Diseases, Pest and Their Economic Importance in Ethiopia. International Journal of Innovation and Scientific Research. Vol. 10 No. 2 Oct. 2014, pp. $527-535$

[15] Hossam, F., Abou-Shara, Martin, S. 2019. Present and future perispectives of using biological agents against pests of honeybees. Egyptian Journal of Biological pests control 29, Article number: 24 (2019).

[16] Jinzhuo, W., Wenshu, L., Xuanyi, P. and Weiguo, L. 2013. A review of Forest Resources and Forest Biodiversity Evaluation System in china. International Journal of Forestry Research, Volume 2013. http://dx.doi.org/10.1155/2013/396345.

[17] Nuru, A., Awraris, G. Ahmed, A. Al-Ghamdi, Amenay, A., Mohammad, J., Ansari, B. and Sarah, R. 2014. Crematogaster chiarinii ants as a potential biological control agent for protecting honeybee colonies from attack by Dorylus quadrates driver ants in Ethiopia (Hymenoptera: Formicidae). Journal of Agricultural and Forest Entomology (2014).

[18] Sebsib, A. and Yibrah, T. 2018. A review on Beekeeping Practice, Opportunities, Marketing and Challenges in Ethiopia. Journal of Dairy and Veterinary Science, Volume 5, Issue 3.

[19] Seid, G. and Solomon, L. 2015. Review on Beekeeping Activities, Opportunities, challenges and Marketing in Ethiopia. Journal of Harmonized Research in Applied Science, 3 (4), 201-214. 
[20] Tavella, J., Alvarez, A. P. and Cagnolo, L. 2018. Determinants of ants species special distribution in habitats from Central Argentina. Community Ecology 19 (3): pp 300-310.

[21] Teklu, G. 2016. Survey on honeybee pests and predators in Sidama and Gedeo zones of Southern Ethiopia with emphasis on control practices. Agriculture and Biology Journal of North America. Vol. 7 (4). Pp 173-181.
[22] Yibrah, T. 2018. A review on: Beekeeping Practice, Opportunities, Marketing and Challenges in Ethiopia. Journal of Dairy and Veterinary Sciences, Vol. 5, Issue 3.

[23] Yoshimasa, ITO. 2014. Local Honey Production Activities and Their Significance for Local People: A Case of Mountain Forest Area of SouthWestern Ethiopia. African Study Monographs, Suppl. 48: 77-97. 